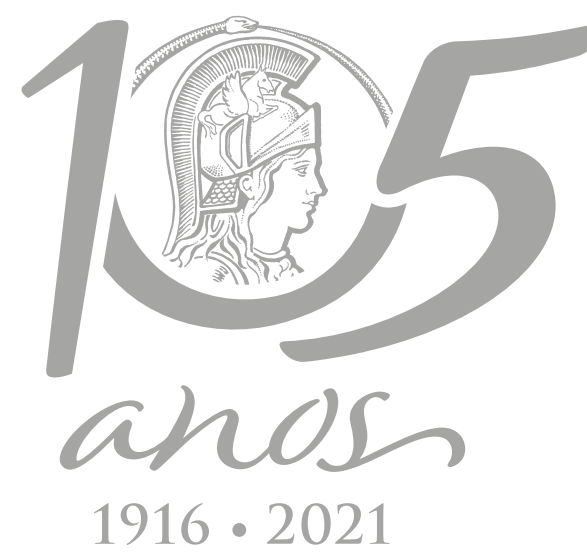

\title{
A combined injectable contraceptive improves plasma redox status and does not induce vascular changes in female rats
}

\author{
LUDMILLA C. DO ESPÍRITO SANTO NERY, LESLIE C.S. BRAZ, LETICIA L.D.M. \\ FERREIRA, FLÁVIA P. VIEIRA, LEANDRO L. DA SILVA, HELENE N.H. BLANC \& \\ JULIANA M. RAIMUNDO
}

\begin{abstract}
This study aimed to investigate the effects of the combined injectable contraceptive $(\mathrm{CIC})$ containing estradiol valerate $(\mathrm{EV})$ and norethisterone enanthate (NET-EN) on aorta function and morphology, as well as on redox status, of female Wistar rats. Female rats (9-10 weeks of age) received intramuscular injections of $\mathrm{CIC}(0.1 \mathrm{mg}$ EV plus $1 \mathrm{mg}$ NET-EN) or castor oil (control group, CTL) for 8 weeks, once a week. Food intake, body weight and systolic blood pressure were measured during the treatment period. Thoracic aortic segments were prepared for isometric tension recording and morphological analysis. Redox status was evaluated by total oxidant status (TOS) and lipid peroxidation (LP) on plasma and reduced glutathione (GSH) on whole blood. $\mathrm{CIC}$ group presented lower food intake and lower total weight gain compared to CTL group. There was no change in systolic blood pressure, vascular response of aorta to phenylephrine and acetylcholine and aorta thickness. Plasma TOS and LP values were reduced in $\mathrm{CIC}$ group, although GSH was not altered. It was shown that the longterm treatment with the CIC containing EV plus NET-EN does not induce endothelial dysfunction and histomorphometric changes of vascular wall, as well as improves redox status on female Wistar rats.
\end{abstract}

Key words: combined injectable contraceptive, estradiol valerate, norethisterone enanthate, oxidative stress, vascular morphology, vascular reactivity.

\section{INTRODUCTION}

The development of effective contraceptive methods represented a milestone for the control of fertility and a gain for public health. Modern methods of contraception, which include hormonal contraceptives, play a crucial role in family planning and in the improvement of reproductive health (Cahill et al. 2018).

Combined oral hormonal contraceptives (COCs), which contain an estrogen and a progestin, are the most commonly used hormonal contraceptives worldwide (Regidor 2019). Ethinyl estradiol (EE) is the most commonly used estrogen in COCs, while there are several available progestins derived from 17-OH-progesterone, 19-nortestosterone, or spironolactone (Fruzzetti et al. 2012, Sitruk-Ware \& Nath 2013).

Although the endogenous female hormones, specially $17 \beta$-estradiol (E2), have protective effects on the cardiovascular system (Knowlton \& Lee 2012, dos Santos et al. 2014), COCs are associated with increased risk of arterial and venous thrombosis (Farmer et al. 2001, de Bastos et al. 2014). EE dose plays an important role in the risk of thrombotic events, while 
second-generation progestins are considered safer than third-generation progestins (de Bastos et al. 2014). Besides the hypercoagulable state, COCs may promote endothelium dysfunction (Lizarelli et al. 2009), impair lipid profile (Endrikat et al. 2002, Lizarelli et al. 2009), and lead to a pro-oxidant/antioxidant imbalance (Kowalska \& Milnerowicz 2016, Pincemail et al. 2007). Thus, COC use may increase the risk of cardiovascular disease even in healthy women.

Combined injectable contraceptives (CICs) are an alternative to COCs and the use of these contraceptives has increased in developing countries (Darroch \& Singh 2013, Farias et al. 2016). CICs have no first-pass effect and present less effect on liver function. Formulations contain the natural estrogen estradiol, which is less potent and is more rapidly metabolized than $E E$, resulting in pharmacokinetic and pharmacodynamic differences between COCs and CICs. Thus, the same cardiovascular risks could not be assumed for both types of contraceptives (Kochhar 2016).

The CIC containing estradiol valerate (EV) and norethisterone enanthate (NET-EN), which is of monthly use, offers effective contraception and is well tolerated (Toppozada 1994, Bassol et al. 2000). This formulation is widely use in Latin America (Bassol et al. 2000) and is included in Brazilian Women's Health Program, which is part of the Brazilian Public Health System (Farias et al. 2016).

Short-term studies with the EV + NETEN formulation have shown minor effects on hemostatic parameters, blood pressure and lipid metabolism (Haiba et al. 1989, Meng et al. 1990, Kesserü et al. 1991, 1994). However, further studies are needed to better define the long-term cardiovascular effects of this CIC. There is no clear data about its effects on morpho-functional aspects of vessels and on redox status, although endothelial dysfunction and oxidative stress play a crucial role in the development of cardiovascular diseases.

To test the hypothesis that the $\mathrm{CIC}$ containing EV + NET-EN has a safer cardiovascular profile than COCs, we evaluated the impact of this $\mathrm{CIC}$ on vascular reactivity and morphological parameters of aorta, as well as on oxidative stress markers in female Wistar rats.

\section{MATERIALS AND METHODS}

\section{Experimental groups}

Female Wistar rats (9-10 weeks of age) were randomly divided into two groups: control group ( $C T L ; n=12)$, which was treated with weekly intramuscular injections of $20 \mu \mathrm{L}$ castor oil (vehicle); and combined injectable contraceptive group ( $\mathrm{CIC} ; \mathrm{n}=18$ ), which received weekly intramuscular injections of $20 \mu \mathrm{L}$ of $\mathrm{CIC}$ containing $0.1 \mathrm{mg}$ EV and $1 \mathrm{mg}$ of NET-EN, for 8 weeks. This administration period corresponds to approximately five years of use by a woman (Andreollo et al. 2012). Dosage and frequency of $\mathrm{CIC}$ administration were calculated by allometry based on those used by women (Freitas \& Carregaro 2013). The intramuscular injections were performed alternately in the right and left front thigh muscles. Food intake and body weight were measured once a week to calculate food intake by day and total weight gain during the treatment period. Hormonal status was indirectly evaluated by vaginal cytology and uterus weight. Vaginal smears were weekly collected, fixed in 95\% alcohol, and stained by the Papanicolaou method.

All protocols were approved by the Ethics Committee on Use of Animals of the Campus UFRJ-Macaé on 1 September 2016 (license MAC037). Rats were maintained on a 12:12 h light-dark cycle, with controlled temperature (23 $\pm 2{ }^{\circ} \mathrm{C}$ ) and food and water ad libitum. 


\section{Non-invasive blood pressure measurement}

Systolic blood pressure was measured by a noninvasive method using a tail cuff plethysmograph (LE5002; Panlab). Before initiating the experimental protocol, rats were made accustomed to staying in the trap and to the pressure system for twenty minutes during three days. Systolic blood pressure was measured once every two weeks during the experimental period. Rats were gently placed in the trap and were pre-acclimatized for approximately 15 minutes at $30 \pm 2{ }^{\circ} \mathrm{C}$, according to the manufacturer's manual, in order to promote vasodilation and to enable blood pressure measurement. The mean of three measurements was calculated for each rat. All measurements were taken at the same time of day, in a quiet room.

\section{Vascular reactivity evaluation}

The thoracic portion of aorta was dissected and cut into rings of 2-3 mm. Aortic rings were placed in $10 \mathrm{~mL}$ organ chambers containing Krebs-Henseilet solution (in $\mathrm{mM}$ : $\mathrm{NaCl} 118 ; \mathrm{KCl}$ 4.7; $\mathrm{KH}_{2} \mathrm{PO}_{4}$ 1.2; $\mathrm{MgSO}_{4}$ 1.2; $\mathrm{CaCl}_{2} 2.5 ; \mathrm{NaHCO}_{3} 25$; glucose 11; $\mathrm{pH} 7.4)$, continuously gassed with carbogen gas $\left(95 \% \mathrm{O}_{2} / 5 \% \mathrm{CO}_{2}\right)$ and maintained at $37 \pm 0.5^{\circ} \mathrm{C}$. Isometric tension was measured (MLT0201; ADInstruments, Bella Vista, New South Wales, AUS), recorded and analyzed by using LabChart Pro software (ADInstruments, Bella Vista, New South Wales, AUS). After an equilibration period of $90 \mathrm{~min}$, under $9.81 \mathrm{mN}$ tension, the concentration-response curve for phenylephrine (Phe; $10^{-9}$ to $10^{-5} \mathrm{M}$; Sigma-Aldrich, St. Louis, MO, USA) was performed. When the contractile response to Phe reached a plateau $\left(10^{-5} \mathrm{M}\right)$, the concentration-response curve for acetylcholine (ACh; $10^{-9}$ to $10^{-5} \mathrm{M}$; Sigma-Aldrich, St. Louis, MO, USA) was obtained. The response to ACh was expressed as the percentage relaxation of the maximal contraction induced by Phe (Leão et al. 2015).

\section{Morphological and morphometric evaluation of aorta}

Thoracic aortas from CTL and CIC groups were collected, fixed in 10 \% Carson's formaldehyde solution and processed for paraffin embedding (Biotec, São Paulo, SP, BRA). Histological serial sections of $5 \mu \mathrm{m}$ were obtained of each sample and stained with hematoxylin and eosin (HE). Sixteen images from each animal were obtained by using an optical microscope (Olympus DP71, Olympus Optical, São Paulo, SP, BRA) coupled to a digital camera (Olympus BX51, Olympus Optical, São Paulo, SP, BRA). For each aorta section, 5 measurements of the thickness of intima and media tunics and of adventitia tunica (Zaki \& Youssef 2013) were performed using the ImageJ free software (https://imagej.nih.gov/ij/ dowload.html).

\section{Redox status analysis}

Blood samples were collected in heparinized tubes by heart puncture and half sample was centrifuged to obtain plasma.

Total oxidation state (TOS) was measured as described by Erel (2005). To $35 \mu \mathrm{L}$ of plasma were added $225 \mu \mathrm{L}$ of reagent $1(150 \mu \mathrm{M}$ xylenol orange, $0.14 \mathrm{M} \mathrm{NaCl}$ and $1.35 \mathrm{M}$ glycerol in $25 \mathrm{mM}$ $\mathrm{H}_{2} \mathrm{SO}_{4}$ solution). The absorbance at $560 / 800$ $\mathrm{nm}$ was measured using a microplate reader (Asys UVM 340, Biochrom, UK), before and 5 min after addition of $11 \mu \mathrm{L}$ of reagent $2(5 \mathrm{mM}$ ammonium iron (II) sulfate hexahydrate, $10 \mathrm{mM}$ o-dianisidine dihydrochloride in $25 \mathrm{mM} \mathrm{H}_{2} \mathrm{SO}_{4}$ solution). A standard curve was obtained using hydrogen peroxide and results were expressed as hydrogen peroxide equivalents per milligram of protein. Total protein content was measured by a standard bicinchoninic acid assay (BCA) according to the manufacturer's instructions (Sigma-Aldrich, St. Louis, MO, USA).

Lipid peroxidation (LP) was determined by measuring the malondialdehyde (MDA) 
concentration on plasma. To $50 \mu \mathrm{L}$ of each plasma sample was added $50 \mu \mathrm{L}$ of distilled water and $100 \mu \mathrm{L}$ of a solution containing 0.1 $\%$ 2-thiobarbituric acid, $1 \mathrm{~mL}$ of acetic acid and $9 \mathrm{~mL}$ of dimethyl sulfoxide. The mixture was incubated at $70{ }^{\circ} \mathrm{C}$ for 30 minutes and, after cooling, fluorescence was read at 532/585 nm (SpectraMax i3, Molecular Devices, San Jose, CA, USA). The results were expressed as picomoles of MDA per milligram of protein.

The dosage of reduced glutathione (GSH) in whole blood was performed using DTNB (5, 5'-dithio-bis-(2-nitrobenzoic acid). Blood samples were diluted in distilled water (1:2) and centrifuged at 5,000 RPM for 10 minutes. Then, $10 \%$ trichloroacetic acid was added to the supernatant (1:1) and the mixture was centrifuged (5,000 RPM; 10 minutes). To $30 \mu \mathrm{L}$ of the supernatant was added $62.5 \mu \mathrm{L}$ of phosphate buffer (pH 8.0) and $12.5 \mu \mathrm{L}$ of DTNB $3 \mathrm{mM}$. GSH reacts with DTNB to produce a chromophore thionitrobenzoic acid (TNB) that give maximum absorbance at $412 \mathrm{~nm}$ measured using spectrophotometer (Asys UVM 340, Biochrom, UK). The amount of glutathione was calculated using the molar extinction coefficient $13600 \mathrm{M}^{-1}$. $\mathrm{cm}^{-1}$ (Ellman 1959).

\section{Statistical analysis}

Statistical analyses were performed using GraphPad Prism ${ }^{\circledR}$, version 5.0 (GraphPad Software, San Diego, CA, USA). After analysis of normality by Shapiro-Wilk test, data were analyzed using unpaired Student t test or MannWhitney $U$ test. Results were presented as mean \pm standard error of the mean (S.E.M.) if normally distributed, or median and interquartile range (IQR) if non-normally distributed. The halfmaximal effective concentration $\left(E_{50}\right)$ was calculated by non-linear regression analysis and is shown as negative $\log \mathrm{EC}_{50}$ in Molar $\left(\mathrm{pEC}_{50}\right)$. The differences between the groups were considered statistically significant when $\mathrm{P}<0.05$.

\section{RESULTS}

\section{Evaluation of hormonal action}

Animals from $\mathrm{ClC}$ group presented specific vaginal cytology, without the normal cyclical changes, confirming the hormonal effect of the contraceptive. Vaginal cytology showed characteristics of metaestrus and proestrus phases, with cornified cells, some leukocytes and mucus (characteristic of metaestrus), as well as deep cells (characteristic of proestrus) slightly clustered (Fig. 1a). Also, it was observed an increase in relative uterine weight of $\mathrm{CIC}$ rats ( $0.30 \pm 0.02 \mathrm{~g} ; \mathrm{P}<0.001)$ when compared to $\mathrm{CTL}$ rats $(0.17 \pm 0.01 \mathrm{~g})$ (Fig. $1 \mathrm{~b})$. It was observed the presence of fluid inside the uterus, suggesting that the organ edema was the main responsible for the weight increase.

\section{Food intake and body weight}

$\mathrm{CIC}$ rats presented lower daily food intake (CTL: $17.39 \pm 0.67 \mathrm{~g} ; \mathrm{CIC}: 19.37 \pm 0.36 \mathrm{~g} ; \mathrm{P}<0.05)$ and lower total body weight gain (CTL: $61.75 \pm 4.56$ g; CIC: $46.39 \pm 2.85$ g; $\mathrm{P}<0.05)$ compared to $\mathrm{CTL}$ group (Fig. 2).

\section{Non-invasive blood pressure measurement}

As shown in Fig. 3, treatment with $\mathrm{CIC}$ did not induce any significant change in systolic blood pressure during the experimental period when compared to CTL group. Systolic blood pressure was similar in both groups at the beginning (CTL: $131.64 \pm 4.7 \mathrm{mmHg}$; CIC: $127.47 \pm 3.57 \mathrm{mmHg}$; $\mathrm{P}>0.05$ ) and after the 8 -weeks experimental period (CTL: $123 \pm 7$ mm Hg; $\mathrm{ClC}: 130.8 \pm 5.48 \mathrm{mmHg}$; $\mathrm{P}>0.05$ ). 
a

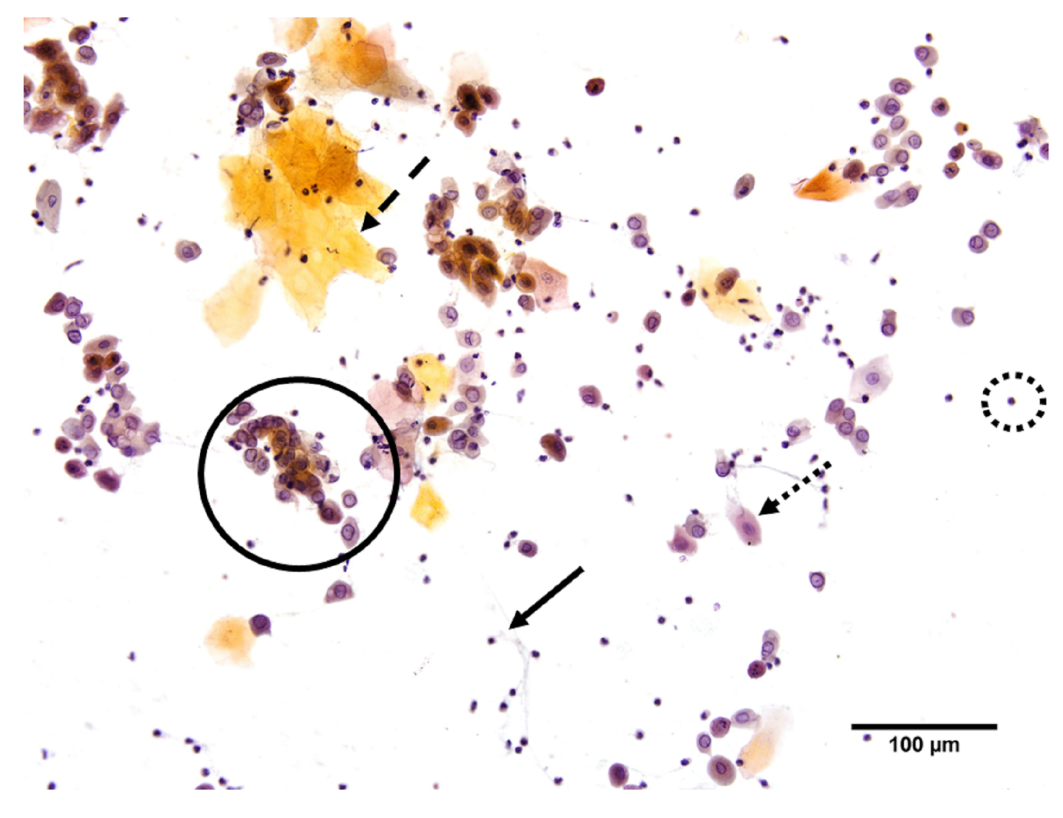

Figure 1. Hormonal status evaluation. a. Representative photomicrograph of vaginal cytology from $\mathrm{CIC}$ rats presenting clustered nucleated epithelial cells (full circle), squamous cells (dashed arrow), leukocytes (doted circle), nucleated epithelial cell (dotted arrow) and mucus (full arrow); Papanicolaou staining. $\mathbf{b}$. Mean \pm S.E.M. of relative uterine weight of rats from CTL $(n=12)$ and CIC $(n=18)$ groups, analyzed by Unpaired Student $t$ test. ${ }^{* * *} \mathrm{P}<0.001$ compared to the CTL group. b

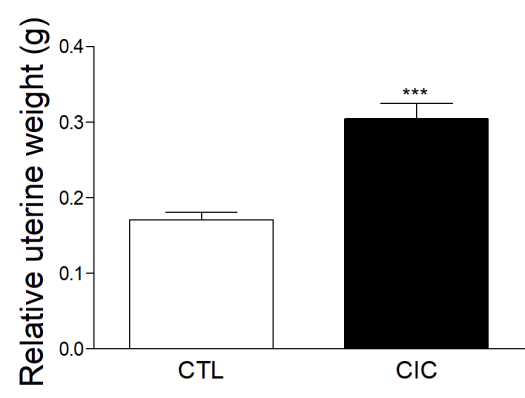

a

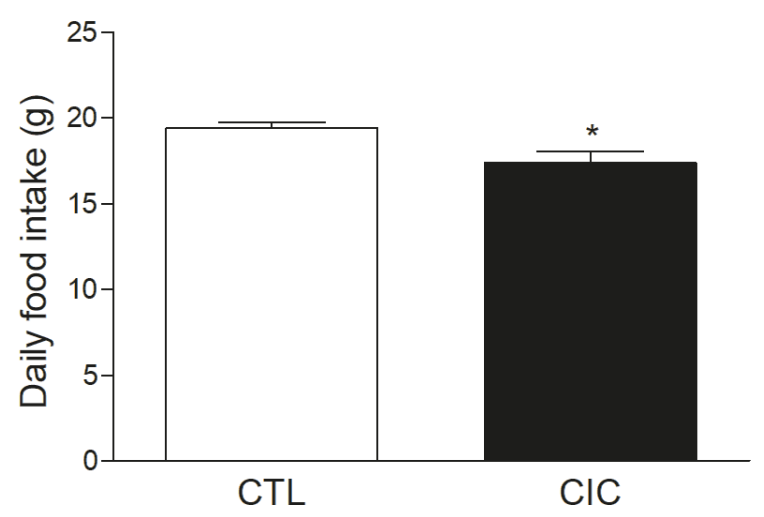

b

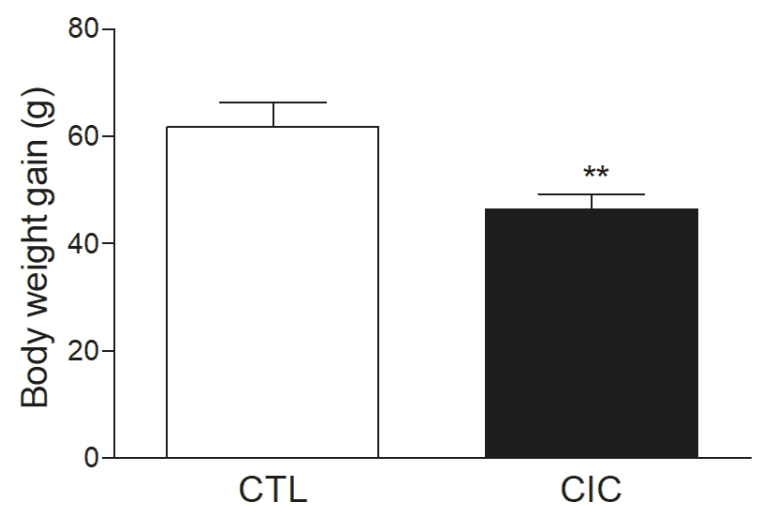

Figure 2. Food intake and total weight gain measurement. a. Daily food intake and $\mathbf{b}$. Body weight gain during the treatment period of CTL $(n=12)$ and CIC $(n=18)$ groups. Data are mean \pm S.E.M, analyzed by Unpaired Student $t$ test. ${ }^{*} \mathrm{P}<0.05$ compared to the CTL group. ${ }^{* *} \mathrm{P}<0.01$ compared to the CTL group. 


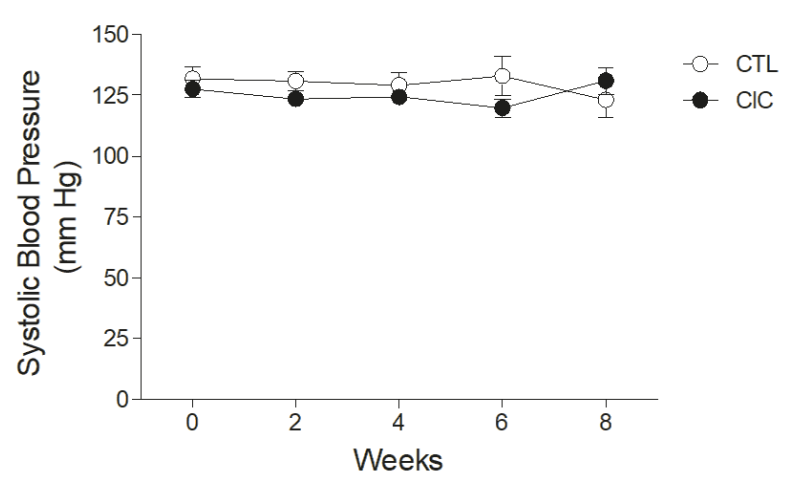

Figure 3. Systolic blood pressure from CTL and CIC groups during the experimental period. Data are expressed as mean \pm S.E.M. (CTL, $n=11$; CIC, $n=17$ ), analyzed by Unpaired Student $t$ test.

\section{Vascular response}

Concentration-response curves for Phe and ACh were obtained in aortas isolated from CTL and $\mathrm{CIC}$ rats. As shown in Fig. 4, there was no difference in the potency of the vasoconstrictor effect of phenylephrine ( $p E C_{50}$ CTL: 7.03 (6.8 7.82); pEC $_{50}$ CIC: 7.27 (6.93 - 7.61); P>0.05) nor in the vasodilator effect of acetylcholine ( $p E C_{50}$ CTL: $\left.7.18 \pm 0.06 ; \mathrm{pEC}_{50} \mathrm{CIC}: 6.95 \pm 0.08 ; \mathrm{P}>0.05\right)$. In addition, maximal contraction produced by Phe (CTL: $14.3 \pm 0.6 \mathrm{mN}$; CIC: $15.3 \pm 0.81 \mathrm{mN}$; P>0.05) and maximal vasodilation produced by ACh (CTL: $85.24 \pm 2.15 \%$; CIC: $82.92 \pm 1.61 \%$; P>0.05) were not statistically different between groups.

\section{Morphological and morphometric evaluation of aorta}

Morphological changes were not observed in the intima, media and adventitia tunics in both groups (Fig. 5a-d). Morphometric analysis (Fig. $5 \mathrm{e}-\mathrm{g})$ showed that total aorta thickness was similar in CTL (107924 (98535 - 111481) $\mu \mathrm{m})$ and

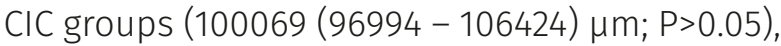
as well as tunica adventitia thickness (CTL: 25955

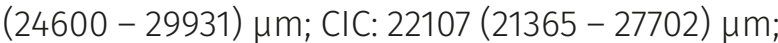
P>0.05) and intima-media thickness (CTL: 78969

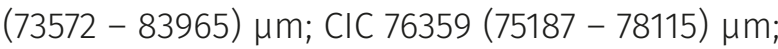
$\mathrm{P}>0.05)$.

\section{Evaluation of redox status}

At the end of the $\mathrm{CIC}$ treatment, TOS (Fig. 6a) was lower in the $\mathrm{CIC}$ group $\left(4.60 \pm 0.71 \mathrm{pmol} \mathrm{H}_{2} \mathrm{O}_{2}\right.$ eq/mg ptn; $P<0.05)$ than in CTL group (10.78 \pm $2.87 \mathrm{pmol} \mathrm{H}_{2} \mathrm{O}_{2} \mathrm{eq} / \mathrm{mg}$ ptn). Similar results were found for LP in plasma, where MDA concentration was $16.78 \pm 1.99 \mathrm{pmol} / \mathrm{mg}$ ptn and $11.99 \pm 0.86$ pmol/mg ptn $(P<0.05)$ for CTL and CIC groups, respectively (Fig. 6b). On the other hand, whole blood GSH (Fig. 6c) was not statistically different between groups (CTL: $80.38 \pm 11.59 \mu \mathrm{mol} / \mathrm{L}$; CIC: $88.42 \pm 8.41 \mu \mathrm{mol} / \mathrm{L} ; \mathrm{P}>0.05)$.

\section{DISCUSSION}

The present study showed that the 8-week treatment of female rats with the $\mathrm{CIC}$ containing EV plus NET-EN did not impair vascular morphofunctional parameters and did not alter blood pressure, while improved plasma redox status. A treatment period of 8 weeks in rats corresponds to the use for approximately 5 years by a woman (Andreollo et al. 2012), thus, this work contributes to a better understanding of the cardiovascular effects of the long-term use of the CIC containing EV plus NET-EN. As far as we know, it is the first study that evaluated the effects of this $\mathrm{CIC}$ on vascular morpho-functional parameters.

Throughout the treatment period, the hormonal action of the $\mathrm{CIC}$ was observed by the characteristic vaginal cytology and confirmed by the increased relative uterine weight. This one is related to the proliferative effect of E2 on endometrium, uterus, and vagina, with increased uterine blood flow and stromal edema (Muhammad et al. 2013).

Although clinical studies have shown that weight gain is one of the side effects of the CIC EV plus NET-EN (Kesserü et al. 1994, Bassol et al. 2000, Gallo et al. 2008), in this study, CIC treatment resulted in lower body weight gain. 
a

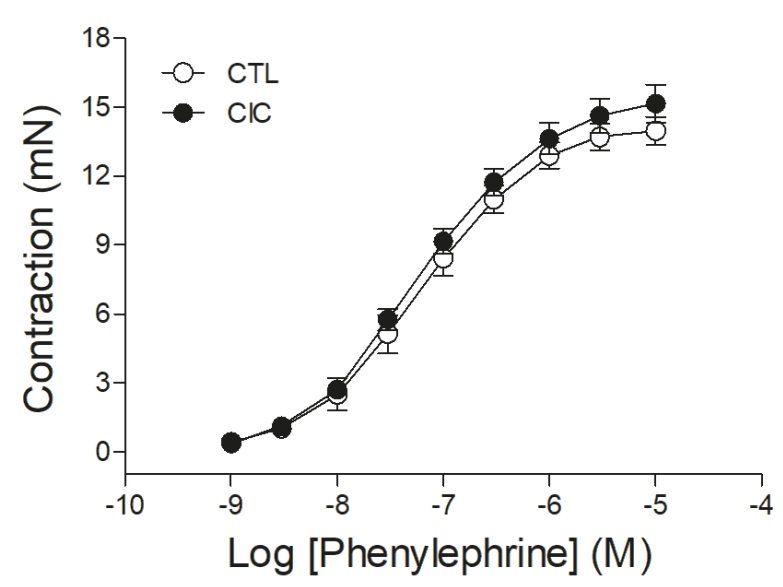

b

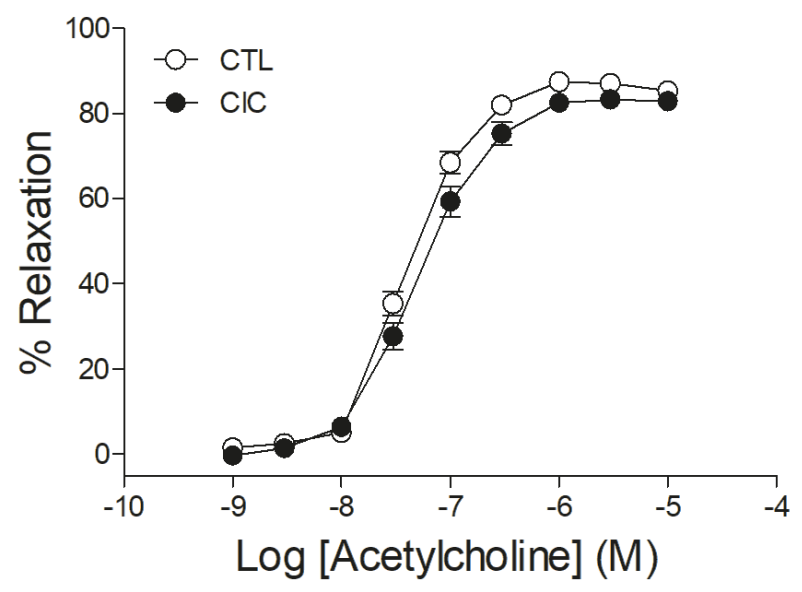

Figure 4. Vascular reactivity of aorta. Concentration-response curves for phenylephrine (a) and acetylcholine (b) in aortic rings isolated from CTL $(n=6)$ and $\mathrm{CIC}(n=9)$ rats after the treatment period. Data are expressed as mean \pm S.E.M.

Similar results have been observed in rats after long-term treatment (Seibert \& Günzel 1994) and in adolescents at 12 months of treatment (Molina et al. 2009). We also observed a reduction in food intake in the CIC group, which could explain, at least in part, the lower body weight gain.

In accordance with clinical studies (Haiba et al. 1989, Kesserü et al. 1991, 1994), we observed that the treatment with the CIC EV plus NET-EN did not alter blood pressure. Furthermore, NET acetate did not cause changes in blood pressure when used alone orally or intramuscularly (Hussain 2004).

Vascular reactivity was evaluated to investigate if the prolonged use of the CIC EV plus NET-EN could lead to endothelial dysfunction, an important risk factor for the development of cardiovascular diseases. No change in vascular reactivity to the vasoconstrictor Phe nor reduction of the endothelium-dependent vasodilation induced by ACh was observed, indicating that vascular function was not impaired. Although progestins with androgenic action may antagonize the protective effects of estrogens, our results indicate that NET-EN does not negatively interfere with the vascular effects of E2, which is in agreement with other studies. It was shown that NET induces endotheliumindependent vasodilation in rat aortic rings and does not reverse the vasodilatory effect of E2 (Perusquía et al. 2003). In endothelial cells from coronary arteries of women, NET did not alter the effect of E2 on markers of endothelial function, such as prostacyclin and endothelin, and markers of atherosclerotic plaque development, such as monocyte chemoattractant protein-1 (MCP-1) (Mueck et al. 2002).

The effects of CICs on the architecture of vascular wall are not defined yet. In relation to injectable contraceptives, we found only 1 study that showed that medroxyprogesterone alone had no effect on intima-media carotid thickness (Lizarelli et al. 2009). We did not observe any morphological or morphometrical changes of the aorta, which corroborates our other results that showed no endothelial dysfunction and arterial hypertension.

Oxidative stress is closely related to the pathophysiology of endothelial dysfunction and is a common feature of cardiovascular diseases 


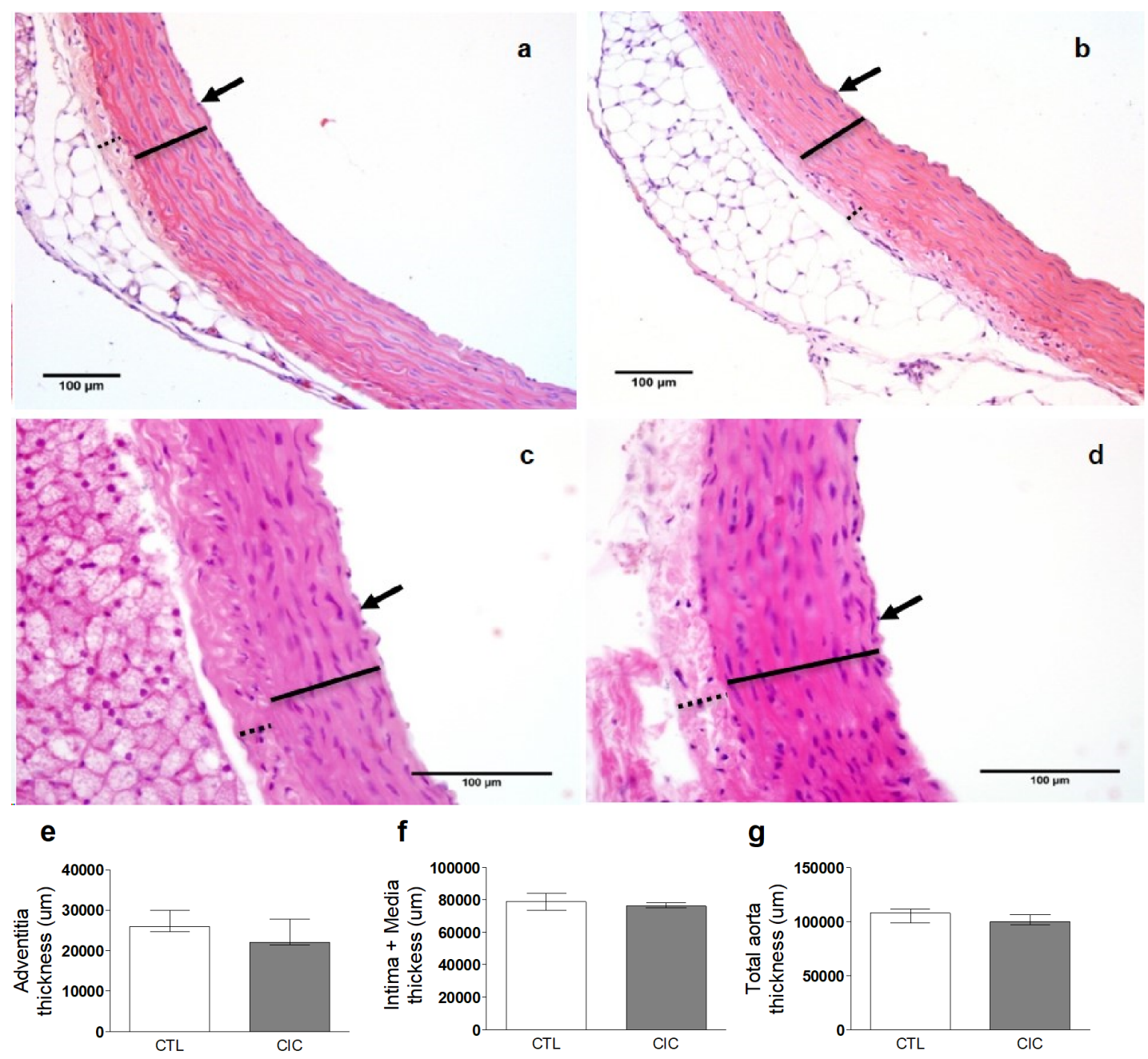

Figure 5. Morphological and morphometric analysis of aorta. Representative photomicrographs of transversal sections of aorta from CTL ( $a$ and $\mathbf{c}$ ) and CIC (b and d) rats showing tunica intima with endothelial cells (arrow), tunica media containing muscle cells (line) and tunica adventitia formed by connective tissue (dotted line). Scale bar $=100 \mu \mathrm{m}$. HE staining. Morphometric evaluation of tunica adventitia thickness (e), tunica intima and media thickness ( $f$ ) and total thickness of aorta (g) from CTL $(n=6)$ and CIC ( $=9)$. Data are expressed as median and interquartile range, analyzed by Mann-Whitney U test.

(Higashi et al. 2009). Circulating MDA levels are increased in patients with hypertension (Rodrigo et al. 2007), abdominal aortic aneurism (Shi et al. 2020) or atherothrombotic disease (Martin-Ventura et al. 2017). MDA modified low-density lipoproteins are a risk marker of the severity of coronary artery disease (Amaki et al. 2004) and are involved in the release of proinflammatory cytokines and smooth muscle cell growth factors, as well as in the impairment of endothelium-dependent vasodilation (Gliozzi et al. 2019). Our results suggest that the contraceptive ameliorate oxidative stress, which could contribute to a favorable cardiovascular profile in long-term use, since $\mathrm{CIC}$ group present decreased TOS levels and LP in plasma, although GSH levels were not significantly altered.

E2 acts as an antioxidant by inhibiting NADPH oxidase expression (Wagner et al. 2001) and by stimulating superoxide dismutase expression 
a

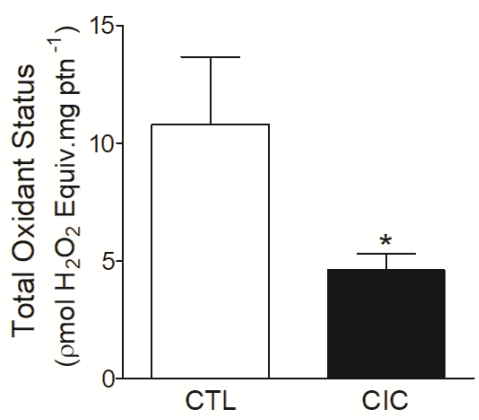

b

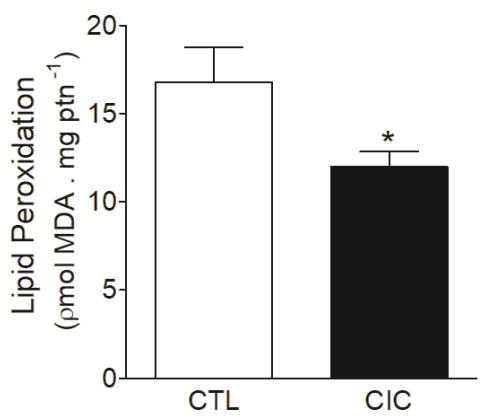

C

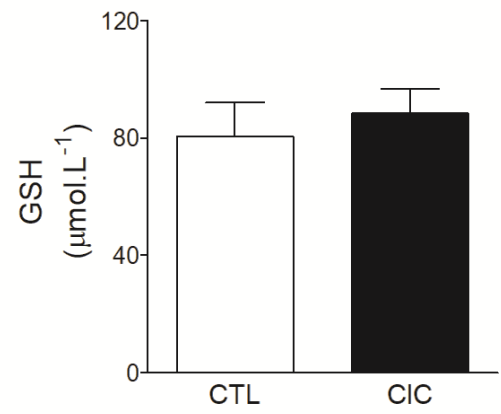

Figure 6. Evaluation of redox status. a. Total oxidant status (CTL, $n=10 ; C I C, n=14$ ), b. Lipid peroxidation (CTL, $n=10 ; C I C, n=14$ ) and c. GSH (CTL, $n=5 ; C I C, n=9$ ) for CTL and CIC groups. Data are mean \pm S.E.M., analyzed by Unpaired Student $t$ test. ${ }^{*} \mathrm{P}<0.05$ compared to the CTL group.

and activity (Strehlow et al. 2003). Moreover, NET acetate reduced lipid peroxidation in the liver and increased activity of SOD and catalase in the liver and kidney (Sissan et al. 1995). Thus, the antioxidant profile of the CIC EV plus NETEN seems to involve both an inhibition of ROS production and an increased activity of the antioxidant enzymatic system.

Different from the CIC EV plus NET-EN, it has been shown that the use of the $\mathrm{COC}$ containing EE and NET by women on fertile period age increased the generation of plasma ROS (Chen \& Kotani 2012, 2018), as well as LP in erythrocytes of adult rats (Köse et al. 1993). Although both contraceptives have NET as a progestin, they differ in the estrogenic component, which may explain this difference in outcomes.

Overall, our data suggest no cardiovascular risk associated with the long-term use of the $\mathrm{CIC}$ containing EV plus NET-EN, and that NET does not antagonize the protective cardiovascular effects of E2. Further studies are necessary to determine the cardiovascular profile of this $\mathrm{CIC}$ in the presence of cardiovascular disease and risk factors, contributing to a better clinical practice.

\section{Acknowledgments}

This study forms part of the M.Sc. thesis of Ludmilla Carvalho do Espírito Santo Nery. This work was supported in part by the Coordenação de Aperfeiçoamento de Pessoal de Nivel Superior - Brazil (CAPES) - Finance Code 001; and the Fundação Carlos Chagas Filho de Amparo à Pesquisa do Estado do Rio de Janeiro (FAPERJ) [grant number E-26/010.002311/2016].

\section{REFERENCES}

AMAKI T ET AL. 2004. Circulating malondialdehyde modified LDL is a biochemical risk marker for coronary artery disease. Heart 90: 1211-1213.

ANDREOLLO NA, SANTOS EF DOS, ARAÚJO MR \& LOPES LR. 2012. Idade dos ratos versus idade humana: qual é a relação? ABCD Arq Bras Cir Dig 25: 49-51.

BASSOL S ET AL. 2000. Mesigyna ${ }^{\circledR}$ once-a-month combined injectable contraceptive: Experience in Latin America. Contraception 61: 309-316.

CAHILL N, SONNEVELDT E, STOVER J, WEINBERGER M, WILLIAMSON J, WEI C, BROWN W \& ALKEMA L. 2018. Modern contraceptive use, unmet need, and demand satisfied among women of reproductive age who are married or in a union in the focus countries of the Family Planning 2020 initiative: a systematic analysis using the Family Planning Estimation Tool. Lancet 391: 870-882.

CHEN J-T \& KOTANI K. 2012. Oral contraceptive therapy increases oxidative stress in pre-menopausal women. Int J Prev Med 3: 893-896.

CHEN J-T \& KOTANI K. 2018. Different Effects of Oral Contraceptive and Dydrogesterone Treatment on Oxidative Stress Levels in Premenopausal Women. J Clin Med Res 10: 146-153. 
DARROCH JE \& SINGH S. 2013. Trends in contraceptive need and use in developing countries in 2003, 2008, and 2012: an analysis of national surveys. Lancet 381: 1756-1762.

DE BASTOS M, STEGEMAN BH, ROSENDAAL FR, VAN HYLCKAMA VLIEG A, HELMERHORST FM, STIJNEN T \& DEKKERS OM. 2014. Combined oral contraceptives: venous thrombosis. Cochrane Database Syst Rev 3: CD010813.

DOS SANTOS RL, DA SILVA FB, RIBEIRO RF \& STEFANON I. 2014. Sex hormones in the cardiovascular system. Horm Mol Biol Clin Investig 18: 89-103.

ELLMAN GL. 1959. Tissue sulfhydryl groups. Arch Biochem Biophys 82: 70-77.

ENDRIKAT J, KLIPPING C, CRONIN M, GERLINGER C, RUEBIG A, SCHMIDT W \& DÜSTERBERG B. 2002. An open label, comparative study of the effects of a dose-reduced oral contraceptive containing $20 \mu \mathrm{g}$ ethinyl estradiol and $100 \mu \mathrm{g}$ levonorgestrel on hemostatic, lipids, and carbohydrate metabolism variables. Contraception 65 : 215-221.

EREL O. 2005. A new automated colorimetric method for measuring total oxidant status. Clin Biochem 38: 1103-1111.

FARIAS MR ET AL. 2016. Use of and access to oral and injectable contraceptives in Brazil. Rev Saude Publica 50: 14 s.

FARMER RDT, LAWRENSON RA, TODD J-C, WILLIAMS TJ, MACRAE KD, TYRER F \& LEYDON GM. 2001. A comparison of the risks of venous thromboembolic disease in association with different combined oral contraceptives. Br J Clin Pharmacol 49: 580-590.

FREITAS GC \& CARREGARO AB. 2013. Aplicabilidade da extrapolação alométrica em protocolos terapêuticos para animais selvagens. Cienc Rural 43: 297-304.

FRUZZETTI F, TRÉMOLLIERES F \& BITZER J. 2012. An overview of the development of combined oral contraceptives containing estradiol: focus on estradiol valerate/ dienogest. Gynecol Endocrinol 28: 400-408.

GALLO MF, GRIMES DA, LOPEZ LM, SCHULZ KF \& D'ARCANGUES C. 2008. Combination injectable contraceptives for contraception. Cochrane Database Syst Rev 4: CD004568.

GLIOZZI M ET AL. 2019. Modulation of nitric oxide synthases by oxidized LDLs: Role in vascular inflammation and atherosclerosis development. Int J Mol Sci 20(13): 3294.

HAIBA NA, EL-HABASHY MA, SAID SA, DARWISH EA, ABDEL-SAYED WS \& NAYEL SE. 1989. Clinical evaluation of two monthly injectable contraceptives and their effects on some metabolic parameters. Contraception 39: 619-632.

HIGASHI Y, NOMA K, YOSHIZUMI M \& KIHARA Y. 2009. Endothelial function and oxidative stress in cardiovascular diseases. Circ J 73: 411-418.
HUSSAIN SF. 2004. Progestogen-only pills and high blood pressure: is there an association? Contraception 69: 89-97.

KESSERÜ EV, AYDINLIK S \& ETCHEPAREBORDA JJ. 1994. Multicentred, Phase III Clinical Trial of Norethisterone Enanthate $50 \mathrm{mg}$ plus estradiol valerate $5 \mathrm{mg}$ as a monthly injectable contraceptive; Final three-year report. Contraception 50: 329-337.

KESSERÜ EV, AYDINLIK S, ETCHEPAREBORDA JJ \& KAUFMANN J. 1991. A multicentred, two-year, phase III clinical trial of norethisterone enanthate $50 \mathrm{mg}$ plus estradiol valerate 5 mg as a monthly injectable contraceptive. Contraception 44: 589-598.

KNOWLTON AA \& LEE AR. 2012. Estrogen and the cardiovascular system. Pharmacol Ther 135: 54-70.

KOCHHAR S. 2016. UK medical eligibility criteria for contraceptive use. Indep Nurse 2016: 16-18.

KÖSE K, DOĞAN P \& OZESMI C. 1993. Contraceptive steroids increase erythrocyte lipid peroxidation in female rats. Contraception 47: 421-425.

KOWALSKA K \& MILNEROWICZ H. 2016. Pro/antioxidant status in young healthy women using oral contraceptives. Environ Toxicol Pharmacol 43: 1-6.

LEÃO VF, RAIMUNDO JM, FERREIRA LL, SANTOS-SILVA JC, VETTORAZZI JF, BONFLEUR ML, CARNEIRO EM \& RIBEIRO RA. 2015. Effects of paternal hypothalamic obesity and taurine supplementation on adiposity and vascular reactivity in rat offspring. Adv Exp Med Biol 803: 749-763.

LIZARELLI PM, MARTINS WP, VIEIRA CS, SOARES GM, FRANCESCHINI SA, FERRIANI RA \& PATTA MC. 2009. Both a combined oral contraceptive and depot medroxyprogesterone acetate impair endothelial function in young women. Contraception 79: 35-40.

MARTIN-VENTURA JL, RODRIGUES-DIEZ R, MARTINEZ-LOPEZ D, SALAICES M, BLANCO-COLIO LM \& BRIONES AM. 2017. Oxidative stress in human atherothrombosis: sources, markers and therapeutic targets. Int J Mol Sci 18(11): 2315.

MENG Y-X, JIANG H-Y, CHEN A-J, LU F-Y, YANG H, SHEN M-YZK-Y, SUN D-L, SHAO Q-X \& FOTHERBY K. 1990. Hemostatic changes in women using a monthly injectable contraceptive for one year. Contraception 42: 455-466.

MOLINA RC, SANDOVAL IZ, MONTERO AV, OYARZÚN PG, MOLINA TG \& GONZÁLEZ EA. 2009. Comparative performance of a combined injectable contraceptive (50 mg norethisterone enanthate plus $5 \mathrm{mg}$ estradiol valerate) and a combined oral contraceptive $(0.15 \mathrm{mg}$ levonorgestrel plus 0.03 mg ethinyl estradiol) in adolescents. J Pediatr Adolesc Gynecol 22: 25-31.

MUECK AO, SEEGER H \& WALLWIENER D. 2002. Medroxyprogesterone acetate versus norethisterone: effect on estradiol-induced changes of markers for 
endothelial function and atherosclerotic plaque characteristics in human female coronary endothelial cell cultures. Menopause 9: 273-281.

MUHAMMAD SI, MAZNAH I, MAHMUD RB, SAEED MI, IMAM MU \& ISHAKA A. 2013. Estrogen receptor modulatory effects of germinated brown rice bioactives in the uterus of rats through the regulation of estrogen-induced genes. Drug Des Devel Ther 7: 1409-1420.

PERUSQUíA M, VILLALÓN CM, NAVARRETE E, GARCíA GA, PÉREZ-PALACIOS G \& LEMUS AE. 2003. Vasodilating effect of norethisterone and its $5 \alpha$ metabolites: a novel nongenomic action. Eur J Pharmacol 475: 161-169.

PINCEMAIL J ET AL. 2007. Effect of different contraceptive methods on the oxidative stress status in women aged 40-48 years from the ELAN study in the province of Liège, Belgium. Hum Reprod 22: 2335-2343.

REGIDOR P-A. 2019. Clinical relevance in present day hormonal contraception. Horm Mol Biol Clin Investig 37: 89-103.

RODRIGO R, PRAT H, PASSALACQUA W, ARAYA J, GUICHARD C \& BÄCHLER JP. 2007. Relationship between oxidative stress and essential hypertension. Hypertens Res 30: 1159-1167.

SEIBERT B \& GÜNZEL P. 1994. Animal toxicity studies performed for risk assessment of the once-a-month injectable contraceptive Mesigyna ${ }^{\circledR}$. Contraception 49: 303-333.

SHI F, MA C, JI C, LI M, LIU X \& HAN Y. 2020. Serum lipid oxidative stress products as risk factors are the candidate predictive biomarkers for human abdominal aortic aneurysms. Clin Appl Thromb Hemost 26. doi: 1076029620932226.

SISSAN MAG, MENON VP \& LEELAMMA S. 1995. Effects of LowDose Oral Contraceptive Oestrogen and Progestin on Lipid Peroxidation in Rats. J Int Med Res 23: 272-278.

SITRUK-WARE R \& NATH A. 2013. Characteristics and metabolic effects of estrogen and progestins contained in oral contraceptive pills. Best Pract Res Clin Endocrinol Metab 27: 13-24.

STREHLOW K, ROTTER S, WASSMANN S, ADAM O, GROHÉ C, LAUFS K, BÖHM M \& NICKENIG G. 2003 Modulation of Antioxidant Enzyme Expression and Function by Estrogen. Circ Res 93: 170-177.

TOPPOZADA MK. 1994. Existing once-a-month combined injectable contraceptives. Contraception 49: 293-301.

WAGNER AH, SCHROETER MR \& HECKER M. 2001. 17ß-Estradiol inhibition of NADPH oxidase expression in human endothelial cells. FASEB J 15: 2121-2130.

ZAKI SM \& YOUSSEF MF. 2013. Thyroid hormone dysfunctions affect the structure of rat thoracic aorta: a histological and morphometric study. Folia Morphol 72: 333-339.

\section{How to cite}

ESPÍRITO SANTO NERY LC, BRAZ LCS, FERREIRA LLDM, VIEIRA FP, DA SILVA LL, BLANC HNH \& RAIMUNDO JM. 2021. A combined injectable contraceptive improves plasma redox status and does not induce vascular changes in female rats. An Acad Bras Cienc 93: e20201924. DOI 10.1590/0001-3765202120201924.

Manuscript received on December 14, 2020;

accepted for publication on January 14, 2021

\section{LUDMILLA C. DO ESPÍRITO SANTO NERY ${ }^{1,2}$}

https://orcid.org/0000-0002-4682-9063

\section{LESLIE C.S. BRAZ ${ }^{2}$}

https://orcid.org/0000-0001-7231-6766

\section{LETICIA L.D.M. FERREIRA ${ }^{1}$}

https://orcid.org/0000-0002-4327-0575

\section{FLÁVIA P. VIEIRA ${ }^{1}$}

https://orcid.org/0000-0001-5688-5838

\section{LEANDRO L. DA SILVA 1}

https://orcid.org/0000-0002-4058-3111

\section{HELENE N.H. BLANC ${ }^{2}$}

https://orcid.org/0000-0001-5729-9785

\section{JULIANA M. RAIMUNDO ${ }^{1}$}

https://orcid.org/0000-0001-9152-4931

${ }^{1}$ Grupo de Pesquisa em Farmacologia de Produtos Bioativos, Universidade Federal do Rio de Janeiro, Campus Macaé Professor Aloísio Teixeira, Rua Aloísio da Silva Gomes, 50, Granja dos Cavaleiros, 27930-560 Macaé, RJ, Brazil

${ }^{2}$ Universidade Federal do Rio de Janeiro, Campus Macaé Professor Aloísio Teixeira, Laboratório de Fisiopatologia, Rua Alcides da Conceição, 159, Vale Encantado, 27933-378 Macaé, RJ, Brazil

Correspondence to: Juliana Montani Raimundo E-mail: julianamontani@gmail.com

\section{Author contributions}

LCESN, LCSB, LLDMF and FPV performed the experiments and analysed the data. LLS, HNHB and JMR designed and supervised the project, and wrote the manuscript with input from all authors.

\section{(cc) BY}

